\title{
ON THE UNINTENDED CONSEQUENCES OF ONLINE TEACHING:
}

\section{A RESPONSE}

\author{
Y. Waghid \\ Department of Education Policy Studies \\ Stellenbosch University \\ Stellenbosch, South Africa \\ https://orcid.org/0000-0003-2565-824X
}

\section{ABSTRACT}

This article is a response to claims that online education is a pedagogical risk for teaching-learning. Of course, notions of privacy, authenticity, and ownership are real challenges to higher education, but these complexities do not have to subvert engaged teaching-learning at higher education institutions. I offer a brief response as to why teaching-learning as a deliberative encounter does not have to be sacrificed with-in online education.

Keywords: teaching, learning, online education, encounters, pedagogy

\section{INTRODUCTION}

Higher education institutions in South Africa have overwhelmingly shifted towards online education, more specifically teaching and learning due to the Covid-19 pandemic. The first article in this issue of the journal alerts readers to some of the risks that teachers, students, and universities might have to consider in expediting online education. In this piece, I respond to some of the risks highlighted in the article pertaining to the implementation of online teaching and learning. In many instances, I concur with the risks higher education institutions might be confronted with, but my critique is about a narrow understanding of teaching-learning that seems to be accentuated as a definitive risk.

\section{IN AGREEMENT WITH SOME OF THE ENUMERATED RISKS FOR ONLINE EDUCATION}

Firstly, the article reminds us that reducing student access to the course or learning materials could result in unauthorised persons (that is, hackers) embarking on unauthorised operations vis-à-vis the materials, teachers and students. This is a real concern, as the potential for using online learning materials for commercial benefit on the part of hackers is an unacceptable 
practice that should not be encouraged.

Secondly, interactive online communication among students and teachers could become vulnerable to inappropriate communicative styles such as trolling, harassment, doxing or even cyberbullying, often directed at seemingly unpopular teachers and students. These actions would be in breach of the universities' code of conduct or communication policies.

Thirdly, the article cautions against malware intrusions and the risk of predatory publishing that can be enhanced through online education. The author warns against the presence of phishing websites for popular platforms like Google Classroom, Zoom, Microsoft Teams and Google Meet on the grounds that users landing on phishing pages are exposed to malicious programmes that can facilitate malware intrusions.

Finally, contentious matters of ownership, privacy, and faking are also raised, which invariably enhance the vulnerabilities of teachers and students to online education. And, as reminded by the author, higher education institutions ought to become more adept at the complexities of the digital economy that impact its pedagogical approaches.

Whereas the above concerns are real and need to be attended to, I am somewhat sceptical about remarks pertaining to teaching and learning in higher education contexts. It is to such a discussion that I now turn.

\section{IN DISAGREEMENT WITH NOTIONS OF ONLINE TEACHING AND LEARNING}

Firstly, while I agree that stable electricity supplies, authentic devices, and reliable internet sources influence the quality of online education, I am somewhat concerned about the pronouncements made about streaming and recordings within a remote teaching-learning environment. If the argument is made that some students might be silenced through streaming and recordings, and teachers' performances might be inhibited due to facing a camera, then such a justification against online teaching-learning seems inadequate. The very act of teachinglearning involves teachers having to provoke students to make sense of course materials and students' potentialities being evoked as a plausible teaching-learning encounter in a higher education context (Waghid 2019). This implies that teachers cannot be asked to perform but are encouraged to evoke students' potentialities. By doing so, they provoke students to think for themselves. Unless teaching-learning is erroneously conceived as teachers transmitting information to students, one would imagine teachers having to perform in a particular way with students sitting like lame ducks waiting to receive information.

Secondly, to equate defensible teaching-learning with favourable classroom announcements as against discussion board announcements is quite inept. Teaching-learning is a pedagogical encounter from which critical moments can arise as a consequence of engaging 
deliberations among teachers and students (Waghid, Waghid, Terblanche, and Waghid 2021). Even an online discussion platform or forum creates opportunities for teachers and students to engage in a deliberative manner. The assumption that pedagogical engagement is more suited for face-to-face tuition is premised on a spurious assumption that teachers should always be the speakers and students the passive listeners.

Thirdly, I agree that unchecked online platforms might encourage student collusion, but then, if online work is not assessed by teachers, implausible and unacceptable teachinglearning-assessment would manifest in any case. Unless teaching-learning-assessment is pursued as a combined pedagogical activity, the pursuit of activist higher education would, in any case, be left wanting (Waghid and Davids 2017).

\section{CONCLUSION}

In this article, I have argued for a notion of online teaching-learning that remains engaging, activist, provocative, and evocative. Of course, cyber-hacking of online course materials is real, but it does not have to subvert human actions such as plausible teaching-learning.

\section{REFERENCES}

Waghid, Y. and N. Davids. 2017. Education, assessment, and the desire for dissonance. New York: Peter Lang.

Waghid, Y. 2019. Towards a philosophy of caring in higher education: Pedagogy and nuances of care. New York: Palgrave-MacMillan.

Waghid, Y., F. Waghid, J. Terblanche, and Z. Waghid. 2021. Higher teaching and learning for alternative futures: A renewed focus on critical praxis. New York: Palgrave-MacMillan. 